\title{
TOWARDS A HOLISTIC AND INCLUSIVE PEDAGOGY FOR STUDENTS FROM DIVERSE LINGUISTIC BACKGROUNDS
}

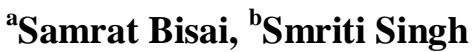 \\ asamratbisaai@gmail.com, ${ }^{\mathrm{b}}$ smriti@iitp.ac.in \\ ${ }^{a}$ Ramakrishna Mission Brahmananda College of Education \\ Mission Para, Punyananda Sarani, Chowdhary Para, \\ Rahara, Kolkata, West Bengal 700118 \\ ${ }^{b}$ Indian Institute of Technology Patna \\ Bihta, Patna 801106 (Bihar)
}

\begin{abstract}
In a multilingual classroom, students come from various cultural, linguistic, and racial backgrounds. They have different ideologies, opinions, and needs. In this regard, 'one size fits all' pedagogy is not only irrelevant but also absurd because the instructions and interactions in the classroom do not cater to the needs of all the students. Therefore, a carefully planned pedagogy that addresses the needs of the individual learners differently in the classroom is needed. In this scenario, implementing multilingual pedagogy in the classroom might be a better idea as it can address the needs of individual learners by making education inclusive and accessible to all. Multilingual pedagogy here is defined as a set of principles that are used to varying degrees in different approaches depending on the teaching context, learners, and curriculum (Neuner, 2004). This paper discusses various approaches, methods, and strategies within the framework of multilingual pedagogy that can be implemented in a classroom consisting of students from diverse linguistic backgrounds. To provide a clear picture of the theoretical ideas, the practical implementation of the ideas in some schools are also discussed. During the implementation, it is indicated that multilingual pedagogy holds the potential to enhance student learning.
\end{abstract}

Keywords: multilingual pedagogy, students, linguistic background

DOI: http://dx.doi.org/10.15639/teflinjournal.v31i1/139-161 
With the advent of globalization, cultural and linguistic diversities are expanding throughout the world. The globalized world has generated extensive linguistic and technological needs across countries, which also influences the educational sector. It has made the teaching-learning discourse more complex and sensitive by challenging the educational discourse of a traditional classroom, which promotes the separationist view of language (Gorter \& Cenoz, 2016). The changing scenario of this globalized world needs a new and different educational approach that will accommodate the diverse cultural and linguistic needs of the students. In this scenario, multilingual pedagogy can be a better option to address the needs and issues of linguistically and culturally diverse students. Multilingual pedagogy is defined as a set of principles that are used to varying degrees in different approaches depending on teaching context, learners, and curriculum (Neuner, 2004). The first part of this paper deals with the existing status of multilingual pedagogy in India. It is followed by a discussion on the gaps in existing literature. The next section discusses the core principles of multilingual pedagogy, which describe fundamental tenants of pedagogy, followed by various approaches and methodology of multilingual pedagogy. Any pedagogy is incomplete without active contributions from the teachers, whose role influences the pedagogy. Consequently, the next section discusses the role of teachers in a multilingual classroom. Finally, the conclusion underlines the effectiveness of multilingual pedagogy in the context of India.

\section{MULTILINGUALISM AND PEDAGOGY IN INDIA}

In India, students come from diverse linguistic and cultural backgrounds. They come to the classroom with different perspectives, cultures, and languages (MacKenzie, 2009). However, the traditional classroom often ignores their linguistic and cultural resources, considering them to be a hindrance in the classroom transactions (Bisai \& Singh, 2018). Classroom transactions mostly take place in the dominant language only. Materials are also designed from the perspectives of dominant language speakers (Mohanty, 2009). As a result, students who come from linguistic minority backgrounds remain unheard of as they cannot comprehend the languages of the dominant groups. Educational outcomes remain extremely poor for minority students who are surviving in mainstream classes. Gradually, they lose interest in education and walk out of the educational system (MacKenzie, 2009). Mohanty 
(2009) remarks that half of the linguistic minority students leave school for linguistic reasons before reaching the fifth class. Therefore, a pedagogy that will address the issues of linguistic diversities by validating the students' first language and culture in the classroom needs to be conceptualized. This kind of pedagogy will make the classroom a better place for students of diverse linguistic backgrounds, and will give them a chance to incorporate their views and opinions in the classroom. It will also help make education accessible to all learners. Hence, there is an urgency to introduce a multilingual pedagogy (García \& Flores, 2012) to bring a radical change in the education system. Multilingual pedagogy should be at the center of the education system as it will meaningfully include all the experiences of the learners in the classroom. Moreover, this pedagogy will aim towards incorporating "traditional values and knowledge system among the indigenous communities" (Mohanty, 2009, p. 9).

Despite having students from diverse cultural and linguistic backgrounds, the teaching pedagogy in India incorporates only one or two languages that are dominant either at a state level or at a national level. This makes the languages of the tribal ${ }^{1}$ students remain suppressed. Although the Education Commission and National Curriculum Framework have supported the implementation of 'three languages formula' to deal with the changing scenario of India (Ministry of Education, 1966; NCERT, 2005), very few attempts have been made to actualize it. It lacks detailed guidelines for proper implementation. In reality most of the teachers always use one language in the classroom, and the rest of the teachers have limited knowledge about multilingual education. As a result, classroom discourse most of the time continues in dominant languages, only thereby ignoring the linguistic resources of the tribal students. This situation has certainly created problems among the tribal language speakers as they cannot comprehend the instructional language of the classroom (MacKenzie, 2009). They remain mute throughout the classroom discourse (MacKenzie, 2009; Mohanty, 2009). A different pedagogical approach is required to address the multiple problems of students coming from tribal areas. In this scenario, implementing multilingual pedagogy in the classroom can address the needs of the individual learners by making learning inclusive and accessible to all.

\footnotetext{
${ }^{1}$ Tribal are ethnic minorities or indigenous communities who have separate languages other than Bengali language
} 
Various scholars have proposed multilingual pedagogy as an alternative pedagogy to manage the linguistic diversity in a classroom (García \& Sylvan, 2011; Korne, 2012; Sachtleben, 2015). They have defined multilingual pedagogy in different terms. Taylor (2010) argues that multilingual pedagogy emerges out of multicultural, heterogeneous, and culturally responsive classroom practices, and it addresses the issues of cultural hybridity, social diversity, and multiple belongingness of the students in an institutional space. It is not a unified methodology, but it consists of principles that are used in various degrees depending on the curriculum, teaching context, and the learners (Haukas, 2016). Sachtleben (2015) opines that multilingual pedagogy should be based on a social practice that is collaborative and should give the students opportunities to bring out their ideas as well as their actions in the classroom. Similarly, García and Flores (2012) acknowledge that multilingual pedagogy should include the learning experiences of the students meaningfully in various socio-educational contexts by developing students' critical consciousness towards their languages. The central focus of multilingual pedagogy is to enhance the efficiency of language learning and to develop the learning awareness of the students across various languages (Haukas, 2016).

Various eminent scholars have strongly argued in favor of promoting multilingual pedagogy in classrooms of the twenty-first century to address the individual needs of the learners (García \& Sylvan, 2011; Taylor, 2010). Though many of the scholars (e.g., Korne, 2012; García \& Sylvan, 2011) accept that addressing the issues of linguistic and cultural diversity together in a classroom is challenging, but it is the need of the hour, especially in the multilingual classroom, to bridge the gap among languages. In a multilingual classroom, students critically explore their languages, identities, and cultures through various curricular topics (Korne, 2012). They negotiate challenging academic content and meaning with each other by using various languages at a time in the classroom (García \& Sylvan, 2011). Giampapa (2010) argues that when students make dialogic interactions with each other, they explore, negotiate, and scaffold their personal and social identity, promote a sense of collaboration and cooperation among themselves. García and Sylvan (2011) state that this pedagogy is dynamically centered around language practices and experiences of the students that certainly address their individuality as well as plurality in a classroom. Bedadur (2013) also mentions that culture and context play an important role in a multilingual classroom. Hence, students should be 
provided with materials that are both culturally relevant and cognitively demanding.

Multilingual pedagogy is multidimensional as it attempts to initiate interactions at a different level: teacher-student, student-student, and studentsparents-teacher (Giampapa, 2010), which positively enhance the quality of education in a multilingual classroom. Hough et al. (2009) also strongly argue in favor of introducing a three-fold engagement in classroom interactions: student-teacher-community. They suggest that classrooms need a new pedagogy that will treat indigenous people as the experts of their culture. The indigeneous people can be engaged in the classroom to impart the indigenous epistemology, which will make the education system more effective. They will also try to choose the content of their teaching and will make a collaborative effort to engage the students through various activities. Taylor (2010) also feels the importance of engaging students, teachers, parents, and the community actively in the multilingual educational process. She explores that a community engagement is necessary for the material development of the indigenous learners as their involvement can prevent misinterpretation as well as the misrepresentation of their culture. Sachtleben (2015) asserts that elders from the indigenous community should be treated as a resource, and they can help the students in the teaching-learning process in a multilingual classroom.

The following researchers endeavor to find suitable strategies and techniques to implement multilingual pedagogy in a classroom. Sachtleben (2015), in his study in New Zealand, has implemented various pedagogical strategies such as pair work, group discussion, report writing, and interpretation of report to make the teaching-learning process better in multilingual classrooms. He has discovered that the students wholeheartedly endorsed these strategies as they had given them a chance for active participation and collaboration in the classroom. While trying to implement multilingual pedagogy in the classroom of the United States, Catalano et al. (2016) have implemented various strategies like critical reflective journaling and collaborative discussion to observe their effectiveness. They discover that multilingual pedagogy influences the students' learning positively as it increases the chance of collaborative discussion and reflective thinking among the students. It also enhances various social skills as well as meta-linguistic awareness among the students. Above all, it addresses the issues of equality as well as social justice in the classroom. 
The abovementioned literatures have discussed the need, importance, and strategies of implementing multilingual pedagogy in the language classroom. However, the strategies or approaches which are proposed by previous scholars have not represented the holistic picture of multilingual pedagogy and are yet to satisfy the needs of teachers and learners in a multilingual classroom. The present paper aims to find the kind of approaches, strategies, or techniques that can be adapted into the pedagogy to make the teaching-learning process better in a multilingual classroom where students come from the diverse linguistic backgrounds. To provide a clear picture of ideas raised in theoretical papers, the researchers have conducted a preliminary study of select schools run by the Government in tribal areas of West Bengal. In this way, the area of study has been limited to the Paschim Medinipur district in the state of West Bengal.

\section{CORE PRINCIPLES OF MULTILINGUAL PEDAGOGY}

Pedagogical principles can be described as the norms or ideas which are necessary to implement pedagogy. An excellent teaching practice or effective teaching always includes sound pedagogical principles as it enhances the quality of education (Carolan et al. 2008; Dandavino et al., 2007; Hativa, 1998). The idea of core principles of multilingual pedagogy, as discussed in the following, has been adapted from the works of García and Sylvan (2011) and Druzhinina et al. (2019).

\section{Principle of Collaboration and Cooperation among Student-Teacher}

Most of the times, the traditional classroom is found to be teacher-centric, where the voices of the students are ignored, especially the voices of the minority students. A visit to schools of Paschim Medinipur district in West Bengal reveals that teachers mostly rely on the 'chalk-talk method' rather than involving students in activities. The students are found to be passive listeners in the classroom. The observation also describes little collaboration between teachers and students in the educational process. The traditional classroom is marked by a lack of collaboration and cooperation among the students and teachers. Thus, a multilingual classroom should aim towards promoting collaboration between teachers and students. When both the teacher and students collaborate with each other, they bring forth multiple perspectives, knowledge, experiences, and talents in the classroom, which make the 
classroom discourse rich (Bisai \& Singh, 2019). Gradually, it enhances mutual understanding among teachers and students, which contributes positively towards effective learning.

\section{Principle of Activity-based Learning and Learner-centered Classroom}

Learners should be placed at the center of the educational process. Their priorities and needs should be given the utmost importance in the classroom. Nevertheless, the researchers find that the tribal schools in West Bengal strictly follow the 'chalk and talk method'. Students are rarely involved in classroom activities, and most of the times they remain silent in the classroom. Teachers mostly stick to the lecture method. In this light, we think teachers should engage their students in various activities in the classroom where they can actively participate in the discourse, negotiate with peers and teachers, and discover meaning. Such activities help the students to bring forward the personal resources into the classroom. Gradually, they start finding a link between home language and school language, which makes the discourse affluent.

\section{Principle of Hybrid Language Practices}

Mixing various languages is a social reality (García, 2009). During a visit to schools in tribal areas in Paschim Medinipur district of West Bengal, the researchers observed that students mixed Santali and Bengali languages in the absence of the teachers. The students seemed to struggle in using only the dominant Bengali in the classroom. However, most teachers have a negative attitude towards the use of Santali in the classroom for two reasons: 1) It is not the language of the majority in the classroom; 2) Teachers cannot understand Santali. Hence, they have created a language boundary in the classroom. Multilingual pedagogy should strictly reject these traditional language boundaries in a classroom as various scholars such as García (2009) and Haukas (2016) have defined language as a fluid system which creates its meaning out of a social context. Hence, mixing various languages in a single classroom discourse or social context is not an absurd phenomenon but a reality of multilingualism (Blackledge \& Creese, 2014). Students, therefore, should be allowed to mix various languages in the classroom as it enhances the possibility of dialogues and interpretations among them (Gutiérrez et al., 1999a; Gutiérrez et al., 1999b). In addition, multilingual teachers should 
promote a learning zone where hybrid language practices will be allowed among the students cordially by considering it to be the resource in the teaching-learning process (Bisai \& Singh, 2019; Gutiérrez et al., 1999a, 1999b).

\section{Inclusion of Different Styles in the Curriculum}

To make the teaching-learning process more effective in a culturally diverse classroom, a teacher should incorporate various learning styles to make the instructions effective. The term 'learning style' can be described as an individual's habitual, natural and preferred way of absorbing, processing, and retaining new skills and information (Oxford, 1998). Keefe (1979) believes that it is an indicator of how learners interact, perceive, and respond to the learning environment. Every individual has different learning styles (Prajapati et al., 2011). They absorb and process knowledge in different ways. If a mismatch occurs between learning styles and teaching styles, instructions become ineffective to the students. Hence, incorporating various learning styles in the teaching-learning process improves the pedagogical model, makes learning more accessible and leads the students to better academic achievement (Graf et al., 2007). The inclusion of various learning styles in the curriculum makes the classroom transactions smooth, attractive, and lively to the students.

\section{Promoting Learner Autonomy}

Formal education system is often not successful in fulfilling the needs of the learners. It has been observed that language classes remain mainly textbook-based and teacher-centric, which fails to provide autonomy to learners (Smith et al., 2017). In this scenario, learner autonomy can be promoted in a multilingual classroom to create a better teaching-learning situation. Learner autonomy is said to be the ability of the learners to take charge of their learning (Holec, 1981). In a multilingual classroom, learner autonomy should be fostered, so that students can engage in the learning process actively by planning, monitoring, evaluating, and assessing their learning. Students need to be actively involved in determining their goals, choosing their learning content, attempting to make the learning content more relevant to their needs, and engaging in various activities with the sense of interests and commitment that make the educational discourse affluent. Chang (2007) claims that promoting learner autonomy in the classroom initiates 
interactions among the students, which creates an interdependent learning environment in the classroom. It also establishes positive group norms among the students, which reinforces their learning. Ho and Crookall (1995) argue that it promotes group spirit among students as they start work and learn in a group, negotiate various ideas with other participants in the classroom, state their views, and develop various skills.

\section{APPROACHES AND METHODS OF MULTILINGUAL PEDAGOGY}

\section{Context and Language Integrated Learning (CLIL)}

CLIL is a unique curricular innovation that offers a new dimension for promoting multilingual education in a heterogeneous classroom. CLIL can be defined as "... a dual-focused educational approach in which an additional language is used for the learning and teaching of both content and language" (Coyle et al., 2010, p. 1). The additional language refers not only to English but also to any language other than the first language, including minority language, second language, or foreign language (Eurydice, 2006; Marsh \& Lange, 1999). Blakemore and Frith (2005) believe that students learn both the subject matter and content simultaneously in a CLIL classroom. It gives the students the opportunity to develop both linguistic and subject knowledge (Dale \& Tanner, 2012; Mathole, 2016).

CLIL can be implemented widely, ranging from pre-school to higher education, specifically in the classrooms where the students come from diverse linguistic backgrounds. Merino and Lasagabaster (2015) point out that it is a powerful tool to boost multilingualism in a classroom. In the CLIL classroom, students learn all the languages simultaneously without hampering their development in the first language (Isidro \& Lasagabaster, 2018). Moreover, it improves the competence in all languages used in the classroom, including majority, minority and foreign languages (Anderson, 2009; Somers, 2017). As Scholey (2015) argues, CLIL removes the barriers among languages, and students use the resources of all languages in the classroom. It does not compartmentalize the languages but engages the students in meaningful tasks through the integration of all languages in the curriculum (Isidro \& Lasagabaster, 2018).

CLIL has various pedagogical benefits in a multilingual classroom. It is a student-centered and innovative pedagogical approach which provides the 
learners with a naturalistic learning environment to use various languages in real-life situation (Kampen et al., 2016; Scholey, 2015). It creates an environment that enhances proficiency both in the target language as well as in the mother tongue (Ludbrook, 2008; Mathole, 2016). It also enhances various skills and confidence in the target language (Dalton-Puffer, 2008). Furthermore, Vázquez and Ordóñez (2018) state that the use of L1 (first language) facilitates the learning of L2 (Second Language) in CLIL classroom. L1 becomes a vehicle to access knowledge which could not be accessed through L2.

To check how the learners are using resources of their mother tongue to enhance the learning of the second language i.e., English, the researchers conducted an activity among sixth class students in a second language classroom of a tribal school in Paschim Medinipur district, West Bengal. The students were asked to produce a text on Durga Puja, which is an important festival for the people of West Bengal. The context of Durga Puja is well known to the people of Bengal. While writing the paragraph in English, the students produced various Bengali lexical items. They were then instructed to classify these lexical items into three categories, i.e. food items, puja items, and items for pandal decoration. The students classified various items according to their category, as shown in Table 1.

Table 1. Lexical Items Produced by Students

\begin{tabular}{l|l|l}
\hline Puja Items & Food Items & $\begin{array}{l}\text { Items for Pandal } \\
\text { Decoration }\end{array}$ \\
\hline Ful (Flower) & $\begin{array}{l}\text { Sondesh (A type of } \\
\text { sweets) }\end{array}$ & Bas (Bamboo) \\
\hline Gamcha (Towel) & Fol (Fruits) & Murti (Idol) \\
\hline $\begin{array}{l}\text { Sharee (A type of Indian } \\
\text { dress) }\end{array}$ & Dove (coconut) & Gach (Saplings) \\
\hline
\end{tabular}

The class was then divided randomly, where students from various linguistic groups (Santali, Lodha, Kurmi, Bengali) were mixed in smaller groups. Now each group was asked to produce a text using a particular category of lexical chunks. The researchers also informed them that they could also use various lexical chunks from their respective culture. When we collected their works, we found words like dhamsa (drum), madal (a type of 
musical instrument), and murup (a flower). At the end of the class, the researchers found out that CLIL had positively influenced both their content and language learning outcomes. It created a naturalistic learning environment in the classroom where the students actively took part in producing a text in the second language. They did not banish their L1 from the classroom, but they used it as a resource in the classroom. They even related their culture and context in the language learning classroom.

\section{Translanguaging}

Translanguaging is one of the essential pedagogical strategies to impart education effectively in the multilingual classroom (Canagarajah, 2011; Makalela, 2015). It is said to be a pedagogical practice where languages are deliberately switched from one language to another to maximize the learning potential of the learners (Garrity et al. 2015). García (2009) opines that it is an act performed by different language speakers to access various linguistic modes and features in order to optimize their communicative potential. It is a meaning-making process which does not only enable students to use resources from various languages, but also validates the knowledge of linguistic minority students in the classroom (Gort, 2015). Translanguaging can also be described as an ideology where the language is fluid, constantly shifting, and creates its meaning out of social discourse (Cenoz \& Gorter, 2017). Hence, it breaks the superficial language boundaries and establishes a new language practice in the classroom, where students can always hover between, across and among languages (García, 2009). Gradually, it creates an environment where a student delimits his language boundaries by creating a translanguaging space in the classroom. When the students intermingle various languages together in the classroom discourse, the communication becomes more diverse, dynamic, and sensitive towards the minority students. One example of translanguaging is cited below, where students are encouraged by the teachers to use various languages in the class to bridge the gap among various languages:

\footnotetext{
Teacher: (showing a picture from the chart) Where is the woman going?

Student 1: She is going to temple.

Student 2: Sa mondir a jaccha puja korar jonno.

(She is going to temple for worshipping)

Teacher: Good! What is she carrying in her hand?

Student 3: A dish
} 
150 TEFLIN Journal, Volume 31, Number 1, January 2020

Student 2: A dish full of fruits

Teacher: How many fruits are there in her plate?

All Students: (in chorus) Five fruits

Teacher: Sobai ak songa uttor dis na. Akhon ai diker chalara amar questioner uttor daba

(Don't give answer together. Now, this row will give the answer of my questions)

Student 5: $\quad$ Duto apple, akta piyara, duto kola

(Two apples, one guava and two bananas)

Teacher: Raghu! Which temple is the woman going to?

Teacher: Bolo (Raghu was silent for a minute)

(Give the answer)

Raghu: $\quad$ Bahu kuri Shiv mandire chalak kana

(The woman is going to Shiv temple)

From the above extract, it is evident that the teacher was trying to initiate the conversation in the classroom to bring out the best in them. Most of the students were taking part actively in the classroom while a Santali student was not engaged in the discourse. Hence, the teacher was trying to encourage the Santali student who certainly had some ideas about the topic but could not express himself due to a linguistic barrier. However, when he was allowed to speak in Santali, he produced a meaningful sentence in Santali language. It proves that Santali students can produce meaningful sentences in the classroom when the teachers support them. Their silence in the classroom was not due to the lack of creative ideas but due to their inability to express their ideas in the dominant languages. In an interview with the researchers, the teachers also opined the same:

They can come out with many creative ideas. But the problem is they cannot express themselves in Bengali or English as they have little exposure to these languages (Bengali and English) in their community. Therefore, they take little more time to learn and become fluent in Bengali.

In this classroom, the teacher was trying to use the linguistic repertoire of the students to elicit information, knowledge, or linguistic resource from the students and was trying to make the classroom interactive. Though the teacher 
did not know Santali, he was giving space to the tribal language speakers to speak in their languages in the classroom.

\section{Code-switching and Code-mixing}

Code-switching and code-mixing are natural phenomena in a multilingual classroom. When students interact with others in a multilingual classroom, students code-switch and code-mix automatically and unconsciously. Codeswitching is known to be an alternative use of two or more languages within a conversation. Essien (1995) defines it as a process in which a speaker changes or switches from one code or language to another, depending mostly on the subject matter, audience, and situation. Similarly, Meisel (1994) states that it is "the ability to select the language according to the interlocutor, the situational context and the topic of conversation, and to change languages within an interactional sequence following socio-linguistic rules and without violating specific grammatical constraints" (p. 415). Scotton and Ury (1977) describe code-switching as a creative act that validates a person's linguistic choice in a social context. Scotton (1982), in another paper, argues that code-switching is a vehicle to negotiate social relationships, maintaining intergroup contacts and motivation to maintain multilingualism in a community.

Code-mixing, on the other hand, is known to be a random alternation of two codes from different languages within a sentence (Ugot, 2010), or in the course of a single utterance (Wardaugh, 1992). These codes could be in the form of lexical items and grammatical features (Muysken, 2000; Rabbani \& Mushtaq, 2012). Code-switching and code-mixing as a communicative strategy often opens a new direction of the conversation in a multilingual classroom. An individual code-switches and code-mixes according to his own preference to fulfill various social functions. When the students code-switch and code-mix in the classroom, they create an environment of collaboration and cooperation, which gradually helps the students to reduce the language boundaries from the classroom by eliminating the gap between home language and school language.

Code-switching and code-mixing also help bring together cultural knowledge and academic knowledge into the same platform of a classroom, maximize the learning potentiality among the students, minimize classroom difficulties and increase critical skills as well as meta-linguistic awareness 
among the students (Canagarajah, 2011). These activities gradually provide the students a chance to select, acquire, create, and use new knowledge (Unamuno, 2008), and they learn to frame a new discourse in the classroom.

A teacher uses code-switching and code-mixing for various purposes. When he tries to motivate a student or try to explain new ideas in the class, he does code-switching and code-mixing. While few teachers code-switch or code-mix in the multilingual classroom to make the classroom lively and attractive, some teachers use it for different purposes in a classroom, such as, to restore peace, harmony and order in the classroom, and to reinforce students' learning (Unamuno, 2008). When the teachers want to discuss the extrapedagogical matter (personal matter, daily happenings) in the classroom, they take recourse to code-switching and code-mixing (Canagarajah, 2011).

The teaching of code-switching and code-mixing should occupy an essential place in the multilingual classroom. To analyze the effectiveness of the code-switching and code-mixing in the multilingual classroom, we produced a mute video. Students were told to reproduce the gist of the video. When the students were narrating the story, they were always code-switching and code-mixing among Bengali, Santali, and English. They mainly used words like daka (rice in Santhali), dress (English), kora (boy in Santhali) jacchi (going in Bengali), and school (English).

In another class, when the students were instructed to produce a text on Indian Independence, they were using lexical chunks both from Bengali and English. The following is an example of intra-sentential code-switching:

Bharat sadhinota payachilo 1947 salar $15^{\text {th }}$ August. Bharater protham prime minister holen Jawaharlal Nehru, jinni akjon prokhato political leader chilan.

(India got independence on $15^{\text {th }}$ August 1947. He was the first prime minister of India and a famous political leader).

While they were conversing in the classroom as they were engaged in the activity, they produced the following sentence, which is an example of intersentential code-switching:

You have to complete the task. Karon ata porikh ta asta para.

(You have to complete the task. The reason is it might be there in the examination). 
Here students used code-switching or code-mixing unconsciously to bridge the gap between languages and to make the classroom discourse smooth and easy for them. It helped them establish their linguistic identity in the classroom. They switched to their mother tongue in English classrooms when they faced any language difficulties in the classroom. In such situations, codeswitching and code-mixing can become an essential approach towards the promotion of multilingual education.

\section{ROLE OF TEACHERS}

Any pedagogical transaction is incomplete without the intervention of teachers, and they play a crucial role in influencing pedagogy in the classroom. Their beliefs and attitudes towards a particular pedagogy influence the teaching-learning process in a classroom. Magos (2006) and Mwanza (2017) found in their studies that teachers play a limited role in using various linguistic repertoires in the multilingual classroom, and have negative attitudes towards the use of minority languages in the educational spaces. Since teachers are the key facilitator in any teaching-learning process, they should cherish positive attitudes towards promoting various languages simultaneously in the multilingual educational space. This attitude will help promote multilingual pedagogy in the classroom. They can also participate in creating a space for communication in diverse or multiple ways, which will enhance the linguistic competencies of the students. Teachers can create an environment where students collaborate and learn from each other, engage them in the meaningmaking process, collectively solve various problems, and develop various social skills through active engagement in the classroom. Apart from these, teachers can openly discuss the issues of diversities in the classroom with the students, which helps them develop a positive attitude towards diversity in the classroom (Cousik, 2015). They can also encourage students to visit nearby communities, which in turn can help them understand social realities and give them a ground to connect their knowledge with the realities of life. The teacher can also train the students in multiple ways to fulfill their cultural and environmental needs by themselves. A teacher trained in using multilingual pedagogy will also treat diversity in a classroom in a practical manner. The following are two examples of how a teacher can play a positive role in a multilingual classroom. 
154 TEFLIN Journal, Volume 31, Number 1, January 2020

\section{Example 1:}

Teacher: (Showing the picture from the chart) How many persons are there in the picture?

$1^{\text {st }}$ Student: Choi Jon (In Bengali)

(Six Persons)

$2^{\text {nd }}$ Student: One girl, two boys, two women and an old man.

All Student: Hai sir (in Bengali)

(Yes sir)

Then, the teacher asked a Santali student (Raghu) to answer.

Teacher: What is the dog doing?

Raghu: (silent for a minute)

Teacher: No problem, you can speak it in Santali.

Raghu: Joma lagit setai ra ra kana

(The dog is barking for food)

Teacher: Can you now translate this sentence into Bengali for your friend?

Raghu: $\quad$ Kukur ta khowar jonno kandcha.

Teacher: Excellent Raghu!

In Example 1, the teacher encouraged the students to take part actively in the classroom discourse by using the various linguistic repertoires of the students. He also motivated the students by praising their contribution in the classroom.

\section{Example 2:}

(The teacher divided the class into four groups. Each group was asked to write a story. The researchers recorded and transcribed one of the stories written by the students).

Student 1: The demon broke the door and entered into the palace.

Student 2: Na, story sobsomay once upon a time diya suru hoi.

(Story always starts with once upon a time)

Student 1: Ha thik

(Yes)

Student 3: Once upon a time, there was a demon.

Student 4: He killed everybody with ... (mumbling)

Student 5: a knife

Student 1: Knife hoba na. Ata valo sunaccha na (It will not be a knife. It does not sound good.)

Student 3: Ata axe hoba. He killed everybody with an axe.

(It will be an axe. He killed everybody with an axe.) 
In the second example, the teacher engaged the students in story writing and group discussion. He only worked as a facilitator in the classroom and monitored the students' progress. The students were arranging the stories, finding suitable words for the story and producing coherent meaning. The teacher encouraged students to use languages meaningfully and coherently in the classroom.

\section{CONCLUSIONS}

Multilingual pedagogy should be an integral part of the present education system as it is progressive, inclusive, and holistic, and satisfies the dynamic needs of students from diverse linguistic and cultural backgrounds. Although the implementation of a multilingual pedagogy in the classroom is challenging and may need an experienced teacher, it is necessary to bridge the gap between language and content and to build a nexus between knowledge and social reality.

Multilingual pedagogy is conceptualized wrongly most of the time by the teachers because of the lack of proper theoretical and empirical knowledge in this area. Hence, this paper aims at helping the teachers find a theoretical foundation in conducting their teaching practices in the multilingual classroom. In order to implement this pedagogy in the classroom, the education system needs experienced teachers who have positive outlooks towards multilingual education systems and those who are sensitive towards their students' educational needs.

\section{REFERENCES}

Anderson, J. (2009). Relevance of CLIL in developing pedagogies for minority language teaching. In D. Marsh, P. Meehisto, D. Wolff, R. Aliaga, T. Asikainen, M. J. Frigols-Martin, S. Hughes, \& G. Lange (Eds.), CLIL practice: Perspectives from the field (pp. 124-132). University of Jyväskylä.

Bedadur, N. V. (2013). An experiment in multilingual pedagogy for English language teacher professional development. In P. Powell-Davies \& P. Gunashekar (Eds.), English language teacher education in a diverse environment (pp. 4-71). British Council. 
156 TEFLIN Journal, Volume 31, Number 1, January 2020

Bisai, S., \& Singh, S. (2018). Rethinking assessment - a multilingual perspectives. Language in India, 18(4), 308-319.

Bisai, S., \& Singh, S. (2019). Bridging the divide: Collaborative learning and translanguaging in multilingual classroom. Fortell - A Journal of Teaching English Language and Literature, 39(2), 46-57.

Blackledge, A., \& Creese, A. (2014). Heteroglossia as practice and pedagogy. In A. Blackledge \& A. Creese (Eds.). Heteroglossia as practice and pedagogy (pp. 1-20). Springer.

Blakemore, S.-J., \& Frith, U. (2005). The learning brain: Lessons for education. Blackwell.

Canagarajah, S. (2011). Codemeshing in academic writing: Identifying teachable strategies of translanguaging. The Modern Language Journal, 95(3), 401-417.

Carolan, J., Prain, V., \& Waldrip, B. (2008). Using representations for teaching and learning in science. Journal of the Australian Science Teachers Association, 54(1), 18-23.

Catalano, T., Shende, M., \& Suh, E. K. (2016). Developing multilingual pedagogies and research through language study and reflection. International Journal of Multilingualism, 15(1), 1-18.

Cenoz, J., \& Gorter, D. (2017). Minority languages and sustainable translanguaging: Threat or opportunity? Journal of Multilingual and Multicultural Development, 38(10), 901-912.

Chang, L.Y.-H. (2007). The influences of group processes on learners' autonomous beliefs and behaviors. System, 35(3), 322-337.

Cousik, R. (2015). Cultural and functional diversity in the elementary classroom: Strategies for teachers. Journal for Multicultural Education, 9(2), 54-67.

Coyle, D., Hood, P., \& Marsh, D. (2010). Content and language integrated learning. Cambridge University Press.

Dale, L., \& Tanner, R. (2012). CLIL activities: A resource for subject and language teachers. Cambridge University Press.

Dalton-Puffer, C. (2008). Outcomes and processes in content and language integrated learning (CLIL): Current research from Europe. In W. Delanoy, \& L. Volkmann (Eds.), Future perspectives for English language teaching (pp. 139-158). Carl Winter.

Dandavino, M., Snell, L., \& Wiseman, J. (2007). Why medical students should learn how to teach. Medical Teacher, 29(6), 558-565. 
Druzhinina, M., Sun, Y., Liu, F., \& Solovyeva, E. (2019). The phenomenon of multilingual pedagogy in education. Advances in Social Science, Education and Humanities Research, 298, 124-128.

Essien, O. E. (1995). The English language and code-mixing: A case study of the phenomenon in Ibibio. In A. Bamgbose, A. Banjo, \& A. Thomas (Eds.), New Englishes: A west African perspective (pp. 260-283). Mosuru Publishers.

Eurydice. (2006). Content and language integrated learning (CLIL) at school in Europe. European Commission. http://www.indire.it/lucabas/ lkmw_file/eurydice/CLIL_EN.pdf

García, O. (2009). Education, multilingualism and translanguaging in the $21^{\text {st }}$ century. In A. Mohanty, M. Pandaa, R. Phillipson, \& T. SkutnabbKangas (Eds.), Multilingual education for social justice: Globalizing the local (pp. 128-145). Orient BlackSwan.

García, O., \& Flores, N. (2012). Multilingual pedagogies. In M. Martin-Jones, A. Blackledge, \& A. Creese (Eds.), The Routledge handbook of multilingualism (pp. 232-246). Routledge.

García, O., \& Sylvan, C. E. (2011). Pedagogies and practices in multilingual classrooms: Singularities in pluralities, The Modern Language Journal, 95(3), 385-400.

Garrity, S., Aquino-Sterling, C. R., \& Day, A. (2015). Translanguaging in an infant classroom: Using multiple languages to make meaning. International Multilingual Research Journal, 9(3), 177-196.

Giampapa, F. (2010). Multiliteracies, pedagogy and identities: Teacher and student voices from a Toronto elementary school. Canadian Journal of Education, 33(2), 407-431.

Gipps, C. (1999). Socio-cultural aspects of assessment. Review of Research in Education, 24, 355-392.

Gort, M. (2015). Transforming literacy learning and teaching through translanguaging and other typical practices associated with "doing being bilingual”. International Multilingual Research Journal, 9(1), 1-6.

Gorter, D., \& Cenoz, J. (2016). Language education policy and multilingual assessment, Language \& Education, 31, 231-248.

Graf, S., Viola, S. R., Leo, T., \& Kinshuk. (2007). In-depth analysis of the Felder-Silverman learning style dimensions. Journal of Research on Technology in Education, 40(1), 79-93. 
Gutiérrez, K. D., Baquedano-López, P., \& Tejeda, C. (1999a). Rethinking diversity: Hybridity and hybrid language practices in the third space. Mind, Culture, and Activity, 6(4), 286-303.

Gutiérrez, K., Baquedano-López, P., Alvarez, H., \& Chiu, M. (1999b). A cultural-historical approach to collaboration: Building a culture of collaboration through hybrid language practices. Theory into Practice, 83(2), 87-93.

Hativa, N. (1998). Lack of clarity in university teaching: A case study. Higher Education, 36(3), 353-381.

Haukas, A. (2016). Teachers' beliefs about multilingualism and a multilingual pedagogical approach. International Journal of Multilingualism, 13(1), 118.

Ho, J., \& Crookall, D. (1995). Breaking with Chinese cultural traditions: Learner autonomy in English language teaching. System, 23(2), 235-243.

Holec, H. (1981). Autonomy and foreign language learning. Pergamon.

Hough, D., Magar, R. B. T., \& Yonjan-Tamang, A. (2009). Privileging indigenous knowledges: Empowering MLE in Nepal. In A. Mohanty, M. Panda, R. Phillipson, \& T. Skutnabb-Kangas (Eds.), Multilingual education for social justice: Globalizing the local (pp. 146-161). Orient BlackSwan.

Isidro, X. S., \& Lasagabaster, D. (2018). The impact of CLIL on pluriliteracy development and content learning in a rural multilingual setting: A longitudinal study. Language Teaching Research, 23(5), 584-602.

Kampen, E. V., Admiraal, W., \& Berry, A. (2016). Content and language integrated learning in the Netherlands: Teachers' self-reported pedagogical practices. International Journal of Bilingual Education and Bilingualism, 21(2), 222-236.

Keefe, J. W. (1979). Learning style: An overview. In J. W. Keefe (Ed.), Student learning styles: Diagnosing and prescribing programs (pp. 1-17). National Association of Secondary School Principals.

Korne, H. D. (2012). Towards new ideologies and pedagogies of multilingualism: Innovations in interdisciplinary language education in Luxembourg. Language and Education, 26(6), 479-500.

Ludbrook, G. (2008). CLIL: The potential of multilingual education. Dos Algarves, 3(17), 18-27. 
Mackenzie, P. J. (2009). Mother tongue first multilingual education among the tribal communities in India. International Journal of Bilingual Education and Bilingualism, 12(4), 369-385.

Magos, K. (2006). Teachers from the majority population-pupils from the minority: Results of a research in the field of Greek minority education. European Journal of Teacher Education, 29(3), 357-369.

Makalela, L. (2015). Moving out of linguistic boxes: The effects of translanguaging strategies for multilingual classrooms. Language and Education, 29(3), 200-217.

Marsh, D., \& Langé, G. (Eds.). (1999). Implementing content and language integrated learning $-A$ research-driven foundation course reader. TIECLIL, Milan; University of Jyväskylä.

Mathole, Y. (2016). Using content and language integrated learning (CLIL) to address multilingualism in South African schools. European Journal of Language Policy, 8(1), 57-77.

Meisel, J. (1994). Code-switching in young bilingual children: The acquisition of grammatical constraints. Studies in Second Language Acquisition, 16(4), 413-440.

Merino, J. A., \& Lasagabaster, D. (2015). CLIL as a way to multilingualism. International Journal of Bilingual Education and Bilingualism, 21(1), 7992.

Ministry of Education (1966). The education commission (1964-66), New Delhi. https://archive.org/stream/ReportOfTheEducationCommission196466D.S.KothariReport/48.Jp-ReportOfTheEducationCommission196466d.s.kothari_djvu.txt

Mohanty, A. K. (2009). Multilingual education - a bridge too far? In A. K. Mohanty, M. Panda, R. Phillipson, \& T. Skutnabb-Kangas (Eds.), Multilingual education for social justice: Globalizing the Local (pp. 5-17). Orient BlackSwan.

Muysken, P. (2000). Bilingual speech: A typology of code-mixing. Cambridge University Press.

Mwanza, D. S. (2017). Implications of teachers' attitudes towards unofficial languages on English language teaching in multilingual Zambia. Zambian Journal of Language Studies, 1(1), 101-124.

NCERT. (2005). National Curriculum Framework, National Council of Educational Research and Training, New Delhi. 
160 TEFLIN Journal, Volume 31, Number 1, January 2020

Neuner, G. (2004). The concept of plurilingualism and tertiary language didactics. In B. Hufeisen \& G. Neuner (Eds.), The plurilingualism project: Tertiary language learning-German after English (pp. 13-34). Council of Europe.

Oxford, R. (1998). Style analysis survey (SAS): Assessing your own learning and working styles. In J. M. Reid (Ed.), Understanding learning styles in the second language classroom (pp. 179-186). Prentice Hall Regents.

Prajapati, B., Dunne, M., Bartlett, H., \& Cubbidge, R. (2011). The influence of learning styles, enrolment status and gender on academic performance of optometry undergraduates. Ophthalmic \& Physiological Optics, 31(1), 69-78.

Rabbani, R., \& Mushtaq, H. (2012). Gender difference in code-switching and code-mixing in text messages of undergraduate students. Language in India, 12(1), 346-356.

Sachtleben, A. (2015). Pedagogy for the multilingual classroom: Interpreting education. The International Journal for Translation \& Interpreting Research, 7(2), 51-59.

Scholey, M. (2015). Integrating English with content learning in wet-weather conditions in Indian primary schools. In G. Pickring \& P. Gunashekar (Eds.), Ensuring quality in English language teacher education (pp. 5360). British Council.

Scotton, C. M. (1982). The possibility of code-switching: Motivation for maintaining multilingualism. Anthropological Linguistics, 24(4), 432-444.

Scotton, C. M., \& Ury, W. (1977). Bilingual strategies: The social functions of code-switching. International Journal of the Sociology of Language, 1977(13), 5-20.

Smith, R., Kuchah, K., \& Lamb, M. (2017). Learner autonomy in developing countries. In A. Chik, N. Aoki, \& R. Smith (Eds.), Autonomy in language learning and teaching (pp. 7-27). Palgrave Macmillan.

Somers, T. (2017). Content and language integrated learning and the inclusion of immigrant minority language students: A research review. International Review of Education, 63(4), 495-520.

Taylor, S. E. (2010). MLE policy and practice in Nepal: Identifying the glitches and making it work. In K. Heugh \& T. Skutnabb-Kangas (Eds.), Multilingual education works: From the periphery to the centre (pp. 2042019). Orient BlackSwan. 
Bisai \& Singh, Towards a Holistic and Inclusive Pedagogy 161

Ugot, M. (2010). Language choice, code switching and code mixing in biase. Global Journal of Humanities, 8(2), 27-35.

Unamuno, V. (2008). Multilingual switch in peer classroom interaction. Linguistics and Education, 19(1), 1-19.

Vázquez, V. P., \& Ordóñez, M. D. C. R. (2018). Describing the use of the L1 in CLIL: An analysis of L1 communication strategies in classroom interaction. International Journal of Bilingual Education and Bilingualism, 22(1), 35-48.

Wardhaugh, R. (1992). An introduction to sociolinguistics. Blackwell Publishers. 